\title{
Plagiarism in Higher Education: A Question of Moral Development or Sociocultural Influence of Discipline
}

\author{
Anna-Carin Jonsson*, och Kennert Orlenius \\ Department of Education and Behavioural Sciences, University of Borås, Sweden \\ *Corresponding author (Email: Anna-Carin.Jonsson@hb.se)
}

\begin{abstract}
This study investigates firstly the relations between students' moral standards and acceptance of plagiarism, cheating, collaboration and equity of treatment, and secondly, the effects of educational experience and discipline on these factors. The participants were 357 university students, 183 enrolled in the teacher education and 136 informatics students and 35 students of cognitive science/consciousness. The instrument included 29 items and was found valid by factor analyzes. The relations were investigated with Pearson's correlation and variance analyses (ANOVA) in SPSS. The results showed a close to zero relation between students' personal, conventional moral standards and their acceptance of plagiarism. Instead students' moral standards had significant relations toward cheating and equity of treatment. Dependent on educational discipline, teacher education versus informatics, norms and ethical value systems influence not only to what degree students find plagiarism unacceptable, but also in what degree they accept cheating and collaboration.
\end{abstract}

Keywords - Plagiarism, Moral Development, Higher Education, Sociocultural, Cheating

\section{Introduction}

There has been a cry for restraining the "assumed" increase in plagiarism and cheating within an academic context in order to prevent a breakdown of cultural conventions (East, 2010), also called the "moral panic approach" which is often spurred by the media and university management (Sutherland-Smith, 2010). However, the fact that undergraduate students at universities copy sentences, paragraphs or even essays and assignments, what we call plagiarism, may not be proof of moral decay. Instead it might be a question of changing norms that affect text production among students. This study's aim is to investigate if there is a relationship between students' conventional moral standards and their attitudes towards plagiarism as well as cheating and collaboration at higher education. This in order to explore if plagiarism has the same importance as cheating as an moral standard as such and further if new technology develops new moral standards of text production.

The moral development of university students has attracted great attention over the last thirty years, as it seems to increase during their years at higher education (Maeda, Thoma \& Bebeau, 2009). It is suggested that higher moral standards are more common towards the end of a higher education period than in the beginning of it. However, moral standards among students in relation to their acceptance of plagiarism and cheating procedures during college or university are less well explored. More specifically, does plague have the same importance as cheating for those high in conventional moral standards? The new digital technology and information and communication technology (ICT) (Nivala, 2009; Player-Koro, 2012) has changed the way we produce texts, and the first people adapting to the new standards is our students at higher education. This may be part of a general attitude, influenced by the concept of for example "open resource" witch generate new ways of text production such as "remix" suggested by Hansen, Stith and Tesdell (2011). They suggest that remixed texts are more in line with how an ordinary work may function outside the academy where you are supposed to collaborate and cut and paste text. Within the moral panic situation with anti-plague software's used at universities that control the written text by every student we need, as teachers and researchers at higher education, consider alternative explanations. For example some researchers suggest that the problem with plagiarism in higher education is more a question of moral development than of moral decay in a lost generation. That is, the problems with plagiarism that university staff experience as increasing today are suggested to be a natural and necessarily individuation process of testing the limits among our young university students by Austin, Simpson and Reynen (2005).

Voelker, Love and Pentina (2012) summarize previous research on cheating behavior among students in higher education and conclude that 1) cheating students also cheat at 
future workplaces, 2) ethic courses administered to students do not help in changing their ethical or moral value systems and 3) that the pure knowledge of being subjected to anti-plagiarism tools decreases plagiarism. In general, Bazerman and Gino (2012) report that unethical behavior is more present when anonymity is high and the risk of being caught is low. With growing classes of students and less resources in form of teachers all around Europe (Askling, 2012), we can expect anonymity to increase. At the same time it has been found that plagiarism varies in accordance with many different factors such as gender, educational background, experience, subject discipline, age, religious beliefs and culture (Jurdi, Hage \& Chow, 2012; Selwyn, 2008). It is also important to notice the incoherence in plagiarism as such. More specific, some texts can be copied without any punishment where the coping of other texts leads to suspension from university with devastating consequences for the student (Anson, 2011). Here the demands on university staff instructional strategies in teaching the students the rules for plagiarism have become more frequent and intense (Jones, 2011).

This study investigates two important issues for higher education: Firstly, the relations between students' moral standards and acceptance of plagiarism, cheating, collaboration and equity of treatment, and secondly, the effects of educational experience and discipline on these factors. If the norms of text production have changed, then conventional morality should have a different relation with plague compared to cheating activity. And if new standards of text production has been developed within new digital technology (Hansen et al. 2011; Player-Koro, 2012) we might expect that students within these specific areas of different computer sciences approaches more strongly agree and use these newly developed moral standards. We will also try to answer the question whether the level of education has any effect on moral standards and attitudes toward cheating. Maeda et al. (2009) suggests that the educational context can explain moral development among students in higher education as well as that Thoma (2006) shows that the educational level also has effect on moral standards among students. These questions in relation to plagiarism are further explored in this study.

\subsection{Students' Moral Standards}

In order to be able to explain why people behave in an ethical manner, Kohlberg (1984) introduced a theory where moral acts were determined by how sophisticated an individual's moral reasons was. Inspired by Piaget's developmental stage theory, Kohlberg presented a theory of moral reasoning that concerned how children's moral thinking changes as they grow older. In sum, in more developed stages superior moral decisions are supposed to be taken in comparison to those made in less developed stages. The theory consists of three general levels including two stages each, which means that the child can develop through 6 stages in order to reach the highest level of moral reasoning. At the first level (Pre-conventional morality), the child does not use internalized values as bases for judgments, but on anticipated punishments, self-interest and gaining rewards. The second level (Conventional morality) uses social conformity as base for reasoning about morality in that the person strives to adapt to other people's values and maintain good relationships. It is also important to maintain social order, more specifically, follow laws and do one's duty. At the third level (Post-conventional morality), reasoning is based on elaborated, general moral principles agreed on by society where the person also understands that these laws can be changed and that individual rights have to be taken into account also. In the last stage of Kohlberg's theory, the person uses abstracts, ethical principles based on justice and equality in a combination of following one's own conscience as a base for moral judgments. Following this, the research of Thoma (2006) on students shows that they move from Conventional morality to Post-conventional morality during their higher education. One explanation is that students are stimulated to question their personal value systems during their higher educations which involve ethical issues and moral standards. According to Kohlberg (1984) this should instead be an effect of maturation for this age group. However, Maeda et al. (2009) states that when controlling for age, maturation cannot explain the effect of higher education on moral development among students. Passer, Smith, Holt, Bremner, Sutherland and Vliek (2009) concludes that Kohlberg's theory of moral reasoning in general fits empirical findings when it comes to children moving from the first level, the pre-conventional stage, to the second level, the conventional stage, through adolescence. However, not even adults' moral reasoning seems to reach the third level, the post-conventional level, and furthermore, the same person's moral judgments tend to reflect different levels depending on the context. Because of this, research is starting to focus on which particular context stimulates moral reasoning.

Maeda et al. (2009) suggests that different educational environments vary according to what degree of moral issues is present in the curriculum (both formal and informal). Results shows that studies in the social sciences and humanities lead to a more rapid moral development compared to studies in technical fields. According to Rests (1986) cognitive theory approach, the more students are exposed to social theory and ideas about social institutions, the more likely they are to develop their moral standards. However, it is important to also take into consideration that different types of students could experience the same education in different ways, even if stable results show that the educational context needs to be taken into account in order to understand variation in moral development among students at higher education (Maeda $\mathrm{t}$ al., 2009).

Gilligan (1977) stated that Kohlberg's (1984) theory of moral reasoning also contains a male bias in the claim that universal justice was the highest level of moral reasoning. She 
argued that his universal justice was an enterprise for males and that morality theory was not neutral. She presented a theory where she claimed that morality is also about responsibility, relationships and care in opposition to Kohlberg's principles of justice, rights and rules. Where Gilligan (1977) suggests a care orientation to moral reasoning, Kohlberg supports a justice orientation. According to Gilligan these two perspectives are formed in the minds of girls and boys in early childhood, because of their different experiences of attachment. The variation between the two genders stems from the inequality of woman being the primary caretakers in most cultures (Jaffee \& Hyde, 2000). Both girls and boys could adapt to either moral orientation (care or justice) in a society where the two genders share the caretaking of the children equally. However, it is important to notice that, according to Gilligan, it is the context that will form the moral orientation of an individual.

In opposite to Kolhberg and Gilligan's normative approach where morality is seen as a personality trait (no matter whether it is genetically inherited or socially evolved), Bazerman and Gino (2012) suggest a theory of behavioral ethics. Here the focus is of a descriptive nature, on what people actually believe and how they behave, not how they should think, reason or behave. Within this theory, morality is seen as malleable and the point is made that people repeatedly fail to interpret the situation as moral or ethical when the specific moral decision is taken. This can explain some of the inconsistency in moral actions across situations within the same individual. Research using this theory shows that it is the conflicting relation within a person that is a dominant factor for when and where a person will act in accordance with his/her moral beliefs (Gino, Schweitzer, Mead, \& Ariely, 2011). More specifically, an individual wishes to be seen as a good person and to be socially accepted and is well aware of society's moral norms. However, this can stand against the greedy wish to advance ones self-interest. Bazerman and Gino (2012) find it interesting to explore when and in what situations people can be presumed to act in an ethical or unethical way. This is similar to Nisan's (1991) moral balance model, that suggests that people have a plus and minus balance account when it comes to moral actions, where good deeds increase the balance and bad ones decrease it. Nisan proves that prior good moral acts give a balance account space for ensuing morally bad acts; in other words, raising people's moral self-image can make people act less ethically in the future.

\subsection{Plagiarism}

According to Wittgenstein there are no natural, fixed values, instead it is humans that decide upon the values and this does not necessarily make sense (Phillips, 2001). East (2010) suggests that it could be the procedure of creating meaning that is universal rather than any principles of morality or ethics. But on second thoughts, this relativism could be problematic when plagiarizers state that their behavior is just another normative standard, eventually from the generation that has grown up with the Internet (Jones, 2011). According to Jones many students believe that information on the Internet is public knowledge and that it is not important to make any reference to this type of information. However, the problem is that more or less all texts are reachable on the Internet by now, at least scientific texts. Reyman (2008) remark that the way we see plagiarism among university staff members is in opposition to how students in informatics learn to use texts. And as mentioned before, new standards of text production is suggested as the concept of "remix" (Hansen et als, 2011). Gourlay and Deane (2012) found out that some students have difficulties interpreting plagiarism, and that students that are not well integrated with the academia, more specifically, non-traditional students seems to have greater problems than others when it comes to plagiarism. This could be interpreted as that plagiarism has very local frames that only holds within the context of higher education, which is another problem.

Anson (2011) presents an explanation of plagiarism based on New Literacy Studies and activity theory which points to the fact that writing takes place in a sociocultural context where "/.../ particular practices evolve locally based on the purposes and goals of participants, and represents both periods of stasis and normativity as well as flux, contestation, and evolution." (p.33, Anson, 2011). According to activity theory, we need to take into account the power relations between humans, their drives and wants, their needs and goals and many other things in order to understand human interaction in general and plagiarism specifically. In the academic context, it seems like the social construction of plagiarism, which is based on the ownership of one's writing and text production is essential to survival within the profession. In many other areas attribution to source is unnecessary. Foucault (1991) argues that consenting to norms and standards are in the interest of those who benefit from it. University lecturers that have been trained in the standards of the reference system have reached their positions through hard work. They want to make sure that these formalized norms and standards are not undermined (East, 2010). It appears that the norms for how to use written material are in a stage of change within our society, which could depend on the growing use of the Internet. Another factor is that other groups than the traditional academic have increased their representation at universities. Jurdi et als. (2012) studied what kind of academic behaviors students term dishonest and found a low consensus among the participating students $(\mathrm{N}=321)$ with their self-administered questionnaire. However, some of their results showed that plagiarism was not as bad as general cheating. When it comes to helping a friend, the students showed higher acceptance of this behavior in comparison to when they benefitted from copying the text, which is in line with previous research (Colnerud \& Rosander, 2009). Jurdi et al. (2012) also found a co-relation between what the students experienced as academic cheating and their ethical value system in an academic context and explained this as the social bound theory where personal beliefs mirror the moral values 
impregnated within social norms and laws.

\subsection{Research questions}

The first question concerns whether there is a connection between students' moral standards and their acceptance of plagiarism, cheating, collaboration and equity of treatment. We want to investigate if the relation is the same between students' conventional moral standards and their attitude to plagiarism in comparison to other conventional standards as cheating and collaboration. The second question involves if educational context (teacher versus informatics program) and educational experience (year one versus three) has any effects in that Selwyn (2008) found that university students within computer science had a tendency to plagiarize to a larger extent than other students, and that students' plagiarism decreased from year one to year three. We are investigating the effect of discipline (students from the teacher education and in informatics) and experience (year one at the university and year three). This is also in line with Maeda et al's (2009) results on moral development in different educational contexts. Reymann (2008) describes how rules about plagiarism violate learning to write among technical communication students trying to explain the acceptance within this group toward plagiarism and/or interaction effects on students' moral standards, acceptance of plagiarism, cheating, collaboration and equity of treatment.

\section{Method}

\subsection{Participants}

The participants were 357 university students of which 183 were enrolled in the teachers educational program,136 were students of informatics, 12 were students of cognitive science and 23 were students of consciousness at the same university in Sweden (3 missing values in the variable program). 226 students were born between 1983-199-, 72 students were born 1973-1982 and 45 students was born 1972 - or earlier (14 missing values in the age variable). To further describe the sample, there were 191 female and 161 male participants in the study (5 missing values in the variable gender). 250 students were studying in their first year and 105 were studying in their last year (2 missing values in the variable of year).

\subsection{Measures}

The instrument included 29 items in three different parts (see Appendix 1). The first part consisted of 10 items about plagiarism, cheating and collaboration and had been previously developed and found valid by Colnerud and Rosander (2008) see also Mavrinac, Brumini, Bilic-Zulle and Petrovecki (2010). An example of one statement about collaboration is "To summarize course literature for each other instead of reading it by yourself"'. The third part of the instrument consisted of 12 cases of plagiarism. A 5-grade interval scale was used in part one and part three in which acceptance of plagiarism, collaboration and cheating was presented to the participants in the following way; 1 stood for low acceptance of plagiarism, collaboration and cheating in general "This is absolutely cheating" and 5 stood for high acceptance of plagiarism, collaboration and cheating in general "This is absolutely not cheating". The second part in the instrument included 7 items about general moral judgments an example of which is "Keeping 1000 Swedish kronor that you found in your wallet". Also in part two a 5-grade interval scale was used in order to estimate the degree of general moral reasoning among the participants in which 1 stand for low moral reasoning "This is absolutely okay" and 5 for high moral reasoning "This is absolutely not okay".

Table 1 presents the factor analysis including the first part with 10 item measuring acceptance of plagiarism in general, collaboration and cheating.

Table 1. A Principal Component Analysis with orthogonal factor loadings (rotated varimax) matrix for the first part including 10 items in the instrument: Plagiarism, Cheating and Collaboration $(\mathrm{N}=348)$.

\begin{tabular}{cccc}
\hline Variable & $\begin{array}{c}\text { Factor 1: } \\
\text { Collaboration }\end{array}$ & $\begin{array}{c}\text { Factor 2: } \\
\text { Cheating }\end{array}$ & $\begin{array}{c}\text { Factor 3: } \\
\text { Plagiarism }\end{array}$ \\
\hline Item 8 & .803 & & \\
Item 9 & .792 & & \\
Item 5 & .579 & & \\
Item 6 & .390 & .798 & \\
Item 10 & & .612 & \\
Item 3 & & .604 & \\
Item 7 & & .521 & .789 \\
Item 4 & & & .676 \\
Item 2 & & & \\
Item 1 & & & \\
\hline
\end{tabular}

The principal components analysis was conducted on the correlations of the ten variables. Three factors were initially extracted with eigenvalues equal to or greater than 1.00. The orthogonal rotation of the factors yielded the factor structure given in Table 1 above. The first factor accounted for $22.4 \%$ of the variance. The four collaboration items loaded onto this factor and the Chronbach's alpha was .676. The second factor accounted for $17.7 \%$ of the variance. The four cheating items loaded onto this factor and Chronbach's alpha was .577. The third factor accounted for $16.0 \%$ of the variance. The two acceptance-of-plagiarism items loaded onto this factor and the Chronbach's alpha was .517. The first factor seems therefore to represent collaboration, the second cheating and the third acceptance of plagiarism. For each factor, the single variables that were loading on the specific factor were collapsed to one single variable. For example, the four items included in the collaboration factor was summed and divided by four, creating a general variable of Acceptance of Collaboration in order to check the existence of measurement error. The same procedure was performed on the other two dimensions, creating one general variable of Acceptance of Cheating and 
one for Acceptance of Plagiarism. These were used in the correlational and variance analyses (see the Result section).

Table 2 presents the factor analysis including the second part with six item measuring Moral Judgments and Equity of Treatment.

Table 2. A Principal Component Analysis with orthogonal factor loadings (rotated varimax) matrix for the second part including 6 items in the instrument: Moral judgments and equity of treatment $(\mathrm{N}=348)$.

\begin{tabular}{ccc}
\hline Variables & $\begin{array}{c}\text { Factor 1: } \\
\text { Moral judgments }\end{array}$ & $\begin{array}{c}\text { Factor 2: } \\
\text { Equity of treatment }\end{array}$ \\
\hline Item 14 & .786 & \\
Item 12 & .659 & \\
Item 15 & .657 & \\
Item 17 & .619 & \\
Item 16 & & .847 \\
Item 13 & & .843 \\
\hline
\end{tabular}

Here, the principal components analysis was conducted on the correlations of the six variables. Two factors were initially extracted with eigenvalues equal to or greater than 1.00. Orthogonal rotation of the factors yielded the factor structure given in Table 2 above. The first factor accounted for $31.88 \%$ of the variance. The items measuring moral standards loaded onto this factor and the Chronbach's alpha was .668. The second factor accounted for $27.8 \%$ of the variance. The two Equity of Treatment items loaded onto this factor and Chronbach's alpha was .683. The first factor seems therefore to represent Moral Judgments and the second Equity of Treatment. One named Moral Standards and the other Equity of Treatment.

Table 3. A Principal Component Analysis withorthogonal factor loadings (rotated varimax) matrix for the third part including 11 items in the instrument: plagiarism and moral judgments $(\mathrm{N}=348)$.

\begin{tabular}{cccc}
\hline Variables & $\begin{array}{c}\text { Factor 2: } \\
\text { Plagiarism }\end{array}$ & $\begin{array}{c}\text { Mix of moral } \\
\text { and } \\
\text { plagiarism }\end{array}$ & $\begin{array}{c}\text { Factor 3: } \\
\text { Mix of moral } \\
\text { and plagiarism }\end{array}$ \\
\hline Item 19 & .890 & & \\
Item 18 & .872 & & \\
Item 22 & .424 & & \\
Item 20 & .333 & & \\
Item 29 & & .687 & \\
Item 27 & & .629 & .713 \\
Item 25 & & -.609 & .597 \\
Item 23 & & .576 & .427 \\
Item 21 & & & \\
Item 28 & & & \\
Item 26 & & & \\
\hline
\end{tabular}

Table 3 presents the factor analysis including the first part with 11 items (one item was deleted from the analysis due to its being too confusing to the participants) measuring acceptance of plagiarism in general, moral judgments and cheating.

The principal components analysis was conducted on the correlations of the ten variables. Three factors were initially extracted with eigenvalues equal to or higher than 1.00. The orthogonal rotation of the factors yielded the factor structure given in Table 3 above. The first factor accounted for $18.8 \%$ of the variance. The four plagiarism items loaded onto this factor and the Chronbach's alpha was .550. The second factor accounted for $18.0 \%$ of the variance. Moral judgments and cheating items loaded onto this factor and the Chronbach's alpha was .204 that is far from reliable, and because of this the factor was excluded from any further analyses. The third factor accounted for $10.8 \%$ of the variance. Again moral judgment items and cheating items were mixed and the Chronbach's alpha was .172 and because of this. Also, this factor was removed and no further analyses performed on this specific factor. Only the first factor seems to represent acceptance of plagiarism and only this dimension was transformed to a general variable named Acceptance of Plagiarism Case and further explored in the analyses in the Result section.

\subsection{Procedure}

Trained researchers collected the data. The students did not receive any information about the aim of the study before their responses and were asked not to speak to each other. When they had finished each part of the instrument, they were asked not to go back to it. After all the participants had attended to all the items, they received full information about the aim and subject within the study's area, and were thanked for their participation.

\section{Results}

First the correlational analyses were the relationships between the dependent variables: Moral Judgments, Acceptance of Plagiarism in general, Acceptance of Plagiarism Case, Cheating, Collaboration and Equity of Treatment is explored. After that, six 2 (Educational experience: Year 1 versus Year three) x 2 (Discipline: Teacher education versus Informatic education) ANOVAs concerning the dependent variables: Moral Standards, Acceptance of Plagiarism in general, Acceptance of Plagiarism Case, Cheating, Collaboration and Equity of Treatment is presented.

\subsection{Correlations}

Table 4 below describes the Pearson correlation between the dependent variables: Moral Standards, Acceptance of Plagiarism in general, Acceptance of Plagiarism Case, Cheating, Collaboration and Equity of Treatment.

It is important to notice that correlations below $r=0.300$ is too weak to be accepted as a relation between two variables, too little of the variance can be explained in the relation to actually make any contributions to science (Howitt \& Cramer, 2006). Because of this, we don't discuss correlations below 0.300 (or that cannot be summed to .300). 
Table 4. Pearson correlation coefficient for the factors moral judgments, plagiarism general items, plagiarism case items, cheating, collaboration and equity of treatment $(\mathrm{N}=348)$

\begin{tabular}{lcccccc}
\hline & 1. & 2. & 3. & 4. & 5. & 6. \\
\hline 1. Moral judgments & 1 & & & & & \\
2. Plagiarism general & $-.182^{* *}$ & 1 & & & & \\
3. Plagiarism case & $-.179^{* *}$ & $.326^{* *}$ & 1 & & & \\
4. Cheating & $-.310^{* *}$ & $.267^{* *}$ & $.321^{* *}$ & 1 & & \\
5. Collaboration & -.080 & $.447^{* *}$ & $.273^{* *}$ & $.308^{* *}$ & 1 & \\
6. Equity of treatment & $.402^{* *}$ & $-.139^{* *}$ & $-.186^{* *}$ & $-.294^{* *}$ & $-.139 * *$ & 1 \\
\hline
\end{tabular}

Moral Standards have two significant relations that are strong enough to be considered as relevant, one toward Cheating $r=-0.310, p<0.01$, and one toward Equity of Treatment $r=0.402, p<0.01{ }^{1}$ The more important a participant finds it to be following certain moral standards, the less tolerance the same person expresses in regard to Cheating and the less tolerance this person expresses towards Equity of Treatment. In other words, those with high conventional moral standards do not accept cheating at university, and students with low conventional moral standards do not see cheating as such a big problem. However, the students with high conventional morals do not accept people with different ideologies to the same extent as people with lower conventional moral standards. Acceptance of Plagiarism in general has two significant relations, one that is expected towards Plagiarism case $r=326, p<0.01$ which means that those who accept Plagiarism in general behave in the same way in Plagiarism expressed through cases. And the second relation is toward Collaboration $r=.447, p<0.01$ where increased acceptance of plagiarism in general items gives increased acceptance of Collaboration between student friends. Specifically, students who do not see plagiarism as cheating also find it more in order to collaborate among students on different types of exams within higher education. Also Plagiarism in case has a significant relation to Cheating $r$ $=0.321, p<0.01$, the more a student accepts plagiarism the more he/she accepts cheating as well. Two significant relations to Cheating remains, one correlation to Collaboration $r=0.308, p<0.01$ where higher acceptance toward cheating gives higher acceptance of collaborations. And one significant relation to Equity of treatment, $r=-0.294$, $p<0.01$ which means that if a student accepts cheating to a higher extent than the same student is more prone to accept Equity of treatment. No other relations were both strong enough and significant.

\subsection{ANOVA analyzes}

Two, two-way unrelated ANOVA 2 (teacher versus informatics program) x 2 (year one versus year three) was performed on the dependent variables Moral standards and
Equity of treatment (see Table 5 below).

In the first two-way unrelated ANOVA, a significant main effect was found for the dependent variable Moral standards between teacher students $(M=3.36)$ and informatics students $(M=2.62)$ were $F(1,301)=32.87, p<0.001, \eta^{2}=0.10$ suggest that teacher students seems to have higher moral standards compared to students in informatics. In the second two-way unrelated ANOVA with the dependent variable Equity of treatment, two significant main effects were found, the first between the first year of study $(M=3.44)$ and the third year of study $(M=3.00)$ were $F(1,312)=7.30, p<0.01$, $\eta^{2}=0.02$ can be interpreted in that tolerance toward different attitudes and values increase during university studies. The second main effect was between teacher students $(M=3.93)$ and informatics students $(M=2.51)$ where $F(1,312)=$

76.99, $p<0.001, \eta^{2}=0.20$ shows that the teacher students was less tolerant toward different attitudes and values compared to informatics students. No interaction effect was found.

Another four two-way unrelated ANOVAs were computed on the dependent variables Acceptance of plagiarism general items, Acceptance of plagiarism case, Acceptance of cheating and Acceptance of collaboration (se Table 6 below).

For the dependent variable Acceptance of plagiarism general items a main effect was found in the two-way unrelated ANOVA between teacher students $(M=2.19)$ and informatics students $(M=2.84)$ were $F(1,309)=25.83, p<$ $0.001, \eta^{2}=0.08$ which shows that teacher students to a lower degree accept plagiarism compared to students in informatics. Furthermore, an interaction effect showed between teacher students of year one $(M=2.45)$ and of year three $(M=1.90)$ and informatics students of year one $(M=2.81)$ and year three $(M=3.06), F(1,312)=7.28, p<0.01, \eta^{2}=0.03$ which means that teacher students' acceptance of plagiarism decreases during teacher education, whereas students in informatics' acceptance of plagiarism increases during their education.

\footnotetext{
${ }^{1}$ There are two more significant relations between moral standards and plagiarism. However, they are too weak/too close to a zero relation, to be of any importance to research (Howitt \& Cramer, 2006).
} 
Tabel 5.Means and SD from a 2 x 2 ANOVA on the dependent variable moral standards and equity of treatment with between group factor Educational experience (student year one or student year three) and Discipline (teacher educational program or computer/informatics program)

\begin{tabular}{cccc}
\hline Variables & Teachers & Informatics & Total \\
\hline Moral Year one & $3.40(0.99)$ & $2.63(0.91)$ & $2.98(1.02)$ \\
Moral Year three & $3.30(0.82)$ & $2.51(0.68)$ & $3.17(0.85)$ \\
Moral Total & $3.36(0.91) * * *$ & $2.62(0.88)$ & $3.04(0.97)$ \\
\hline Equity of treatment & $4.07(0.89)$ & $2.80(1.27)$ & $3.43(1.28) * *$ \\
$\quad$ Year one & & & $3.00(1.22)$ \\
Equity of treatment & $3.78(1.09)$ & $2.22(0.97)$ & $3.42(1.26)$ \\
$\quad$ Year three & $3.93(0.10) * * *$ & $2.51(1.24)$ & \\
Equity of treatment Total & & & \\
$* * * \mathrm{p}<0.01$ between year one and year three & & & \\
$* * *=\mathrm{p}<0.001$ between teacher students and informatics students &
\end{tabular}

Table 6. Means and SD for the between group factor Educational experience (student year one or student year three) and Discipline (teacher educational program or computer/informatics program) on the dependent variables acceptance of: plagiarism in general items, plagiarism case, cheating and collaboration.

\begin{tabular}{lccc}
\hline \multicolumn{1}{c}{ Variables } & Teachers & Informatics & Total \\
\hline Plagiarism general Year one & $2.45(1.08)$ & $2.81(0.96)$ & $2.65(1.03)$ \\
Plagiarism general Year three & $1.90(0.95)^{* *}$ & $3.06(0.92)$ & $2.09(1.03)$ \\
Plagiarism general Total & $2.19(1.05)^{* * *}$ & $2.84(0.95)$ & $2.46(1.06)$ \\
\hline Plagiarism case Year one & $1.90(0.62)$ & $2.16(0.71)$ & $2.04(0.68)$ \\
Plagiarism case Year three & $1.77(0.62)$ & $2.25(0.56)$ & $1.85(0.63)$ \\
Plagiarism case Total & $1.84(0.62)^{* * *}$ & $2.17(0.69)$ & $1.98(0.67)$ \\
\hline Cheating Year one & $2.91(0.76)$ & $3.66(0.79)$ & $3.32(0.86)$ \\
Cheating Year three & $3.00(0.85)$ & $3.52(0.75)$ & $3.08(0.86)$ \\
Cheating Total & $2.95(0.80)^{* * *}$ & $3.65(0.78)$ & $3.24(0.86)$ \\
\hline Collaboration Year one & $1.98(0.99)$ & $2.26(0.76)$ & $2.14(0.88)$ \\
Collaboration Year three & $2.00(0.88)$ & $2.74(1.01)$ & $2.13(0.94)$ \\
Collaboration Total & $1.99(0.94)^{* * *}$ & $2.50(0.81)$ & $2.13(0.90)$ \\
\hline
\end{tabular}

Only one main effect was found in the two-way unrelated ANOVA on the dependent variable Acceptance of plagiarism case between teacher students $(M=1.84)$ and informatics students $(M=2.17)$ where $F(1,303)=14.50, p<0.001, \eta^{2}=$ 0.05 showed that teacher students had a lower acceptance of plagiarism compared to students in informatics. When analyzed, the variable Acceptance of Cheating the two-way unrelated ANOVA showed one significant main effect between teacher students $(M=2.95)$ and students in informatics $(M=3.65)$ were $F(1,299)=26.05, p<0.001, \eta^{2}$ $=0.08$ suggesting that the teacher students in general had lower acceptance of cheating compared with students in informatics. Lastly, a two-way unrelated ANOVA showed that for the dependent variable Acceptance of Collaboration, the teacher students $(M=1.99)$ differed significantly from the students in informatics $(M=2.50), F(1,309)=15.12, p<$ $0.001, \eta^{2}=0.05$, in that way that the teacher students showed lower acceptance of collaboration in comparison to the students in informatics. No other effects were registered.

\section{Discussion}

First we present our most important results, after this, we discuss it more closely in that we finally draw some conclusions and make some suggestions for the future when it comes to text production in higher education. The resulting zero relation between students' conventional moral standards and their acceptance of plagiarism make us to oppose the suggestions of Austin et al. (2005) that those with higher moral standards would have rejected plagiarism to a higher degree than those with lower conventional morals. Instead the conventional students' rejected cheating to a higher degree, which means that those that adapt to a conventional stage of moral reasoning (believing in the importance of following rules, laws and norms as well as keeping to social order and conforming to other people's value systems) also find it less acceptable to cheat during their studies within higher education but there was no relation between moral and plagiarism. This could mean that cheating at higher education is still a moral accepted convention but plagiarism is not. New ways of text production is created within the coming digital technologies as the concept of remixe (Hansen et als, 
2011) but also attitudes toward ownership of information as the ethical values surrounding the open resource-paradigm and the sharing of information without economic interest will irresistible change standards. If this is happening, we expected the students of informatics, in accordance with Reymann (2008), to have accepted the new standards to a higher degree than other students, her the more conventional teacher students. It is important to confront the beliefs that acceptance of plagiarism among young students is something about a fixed developmental genetic (Kohlberg, 1984) or socially developed (Gilligan, 1977) moral entity/standard. Or that any students that have a higher tolerance about plagiarism are less morally developed. The results show that it is new technology itself that give rice to a changed moral standard about plagiarism as well as collaboration. The interaction effect showed that during studies in informatics, students accepted plagiarism and collaboration to a higher degree their last year at the informatics program compared with students their first year. The effect for teacher students was the opposite, they showed less acceptance for plagiarism and collaboration their last year at the teacher education compared to teacher students their first year. It seems as if the mission with teacher education is to conserve conventional moral standards about text production they have succeeded. However, the students trained in using the new technology have a different approach to both plagiarism and collaboration that might fit better with future ethical values and moral standards for at least those using the tools of new digital technology.

\subsection{Plagiarism}

Plagiarism in individual cases and in general correlated significantly, which indicates certain degree of reliability within this study. However, acceptance of plagiarism also correlated with acceptance of cheating and collaboration, if the students think it is in order to plagiarize a text, it is also more in order to help a student friend with work of study but at the same time it was more in order to cheat at an exam. However, this did not relate to the students moral standards. Those that accepted cheating to a higher degree also accepted collaboration among students to a larger extent and had a higher acceptance of equity of treatment. Voelker et al. (2012) showed that cheating students also cheat at future workplaces. In that only the threat of getting caught (the use of anti-plagiarism tools) reduced plagiarism and not ethical courses, according to Voelker, it seems to suggest that it is not education that is a solution. One interpretation of this could be that the students seem to be fixated at the result not minding how they go ahead reaching it. The focus on competition and concurrence within the neo-liberal value paradigm (Askling, 2012) in combination with a young generation without work all over Europe might have this effect on moral standards and ethical values.

\subsection{Discipline}

In this study, educational context seemed to have a relatively strong influence in that the teacher students had higher conventional moral standards and presently less tolerance toward plagiarism, cheating, collaboration and equity of treatment compared to the students taking the informatics program. This pattern of results is quite stable. Moral development takes place when students have to question their own value-systems during higher education according to Thoma (2006). However, different educational programs seem to have different effects. From a qualitative study of the same sample of students and their verbal comments, Orlenius and Jonsson (submitted), it seems that students' interpretations of whether something is a question of cheating or not is situation-dependent rather than dependent on general, ethical rules. Students did not automatically respond to plagiarism as something immoral. It seems that the students are focused on the purpose of the behavior, where they use a deontological approach (Bazerman \& Gino, 2012) to ethics which means that they evaluate the person's motive for their actions in order to decide whether the act is morally correct or not (see also Vojak, 2006).

We did not measure post-conventional moral standards that according to Maeda et al. (2009) develop during higher education. We only investigated conventional moral standards and these seem to be the same regardless of whether it is in the beginning or the end of the education. However, it differs significant between teacher students and informatics students. The teacher students have a greater preference for conventional moral standards in comparison with the informatics students. According to Passer et al. (2009) moral standards will vary dependent on the context. One reason why the informatics students showed significantly lower conventional morals could be the context of the new technology as such. If informatics students use texts in another way than what is established in a traditional academic context (Reyman, 2008), more specifically, it might not be seen as a crime to re-use texts among informatics and in some other areas in society as such (Anson, 2011), a tolerant atmosphere around text production could appear. This context of tolerance might have influenced the informatics students also regarding other items in the instrument such as morals and collaboration. According to Bazerman and Gino (2012) and Gino and Galinsky (2012) people that are exposed to certain standards within a specific context start to behave in accordance with them. The degree to which people are influenced by social norms depends on the relationship between the initiator and the follower. As these students are in a process of forming a professional identity they will be specifically sensitive to older students studying the same programs and their teachers.

In relation to this, Maeda et al (2009) concludes that the degree to which moral and ethical issues are present in the curriculum will generate different praxis and norms in varying educational contexts and if social theory is frequently 
present during the students' higher education, moral standards will develop more rapidly. The question is what kind of moral standards that are developed? To not share information could for example be a new moral standard. It could be that the teacher education has a curriculum that more strongly expresses ethical values and conventional moral standards within a more conservative norm of text production. The teacher students' acceptance of plagiarism decreased dramatically from their first year to their third year of study in opposition to the informatics students that seemed to increase their tolerance toward plagiarism and collaboration during the same period. Jurdi et al. (2012) suggests that social bound theory could help explain academic cheating in that the students beliefs will mirror the ethical values, social norms and laws in the formal as well as informal curriculum of the discipline (which is the students' educational environment). We reason that the teacher students are to a higher degree influenced by a more conservative value system in comparison to the informatics students. This questioning of value systems has been shown to be one way to change the ethical behavior of students to better match their higher ethical and moral standards according to Bazerman and Gino (2012).

The suggestions from Hansen et al. (2011) of a redefinition of plagiarism toward an interpretation of the concept toward legacy of remixing in text production can be considered. Who are in power when it comes to defining what moral standards we should follow? Anson (2011) explains the social construction of plagiarism through activity theory, which points to the importance of analyzing the power relations within the academic context where the ownership of one's own text is extremely important. It is the university staff with its members that insist on the moral panic approach (Sutherland-Smith, 2010). East (2010) explains that the university lecturers have reached their positions in the systems through adapting to the standards of the reference system and are not interested in losing their positions. As opposed to the informatics students, teacher student will remain in the academic context after graduating and could be viewed as the core building blocks of the total system. This study shows that during their teacher education the rules of plagiarism as an unacceptable activity are strongly enforced by the system

\subsection{Conclusions}

There seems as conventional moral standards are about to change with new technology when it comes to text production as well as if group performance is acceptable or not (collaboration). Different educational contexts with different norms and ethical value systems influence not only to what degree students find plagiarism unacceptable, but also in what degree they accept cheating, collaboration and how important equity of treatment of people are. This fits the behavioral ethic theory (Bazerman \& Gino, 2012) that states the importance of the situation, the context and here specifically, the influence of older students on those who are younger for effects on moral decisions to appear as ethical or unethical. However, if we find it important to define plagiarism in a conservative way, we should learn from the teacher programs in that they successfully decreased the students' acceptance of plagiarism during the education. If we on the other hand find it interesting to understand plagiarism within universities in relation toward a changing society and new technology, we might take greater notice of the informatics students.

\section{References}

Anson, C.M. (2011). Fraudulent Practices: Academic misrepresentations of plagiarism in the name of good pedagogy. Composition Studies, 39, 29-43.

Austin, Z., Simpson, S., \& Reynen, E. (2005). 'The fault lies not in our students, but in ourselves': academic honesty and moral development in health professions education - results of a pilot study in Canadian pharmacy. Teaching in Higher Education, (2)10, 143-156.

Bazerman, M.H., \& Gino, F. (2012). Behavioral Ethics: Toward a deeper understanding of moral judgment and dishonesty. Annual Review of Law and Social Science, 8(2), in press.

Colnerud, G. \& Rosander, M. (2008). Academic dishonesty, ethical norms and learning. Assessment \& Evaluation in Higher Education, 1-12, iFirst Article

East, J. (2010). Judging plagiarism: a problem of morality and conventions. Higher Education, 59, 69-83.

Gilligan, C. (1977). In a different voice: woman's conceptions of self and of morality. Harward Educational Review, 47(4), 481-517.

Gino, F., \& Galinsky, A. (2012). Vicarious dishonesty: when psychological closeness creates distance from one's moral compass. Organizational Behavior and Human Decision Processes. In press.

Gino, F., Schweitzer, M., Mead, N., \& Ariely, D. (2011). Unable to resist temptation: how self-control depletion promotes unethical behavior. Organizational Behavior and Human Decision Processes. 115(2), 191-203.

Gourlay, L. \& Deane, J. (2012). Loss, responsibility, blame? Staff discourses of student plagiarism. Innovations in Education and Teaching International, 49(1), 19-29.

Hansen, B., Stith, D. \& Tesdell, L.S. (2011). Plagiarism: What's the big deal? Business Communication Quarterly, (2), 74, 188-191.

Jaffe, S. \& Shibley Hyde, J. (2000). Gender differences in moral orientation: A meta-analysis. Psychological Bulletin, 126 (5), 703-726.

Jones, D.L.R. (2011). Academic dishonesty: are more students cheating? Business Communication Quarterly, (2), 74, 141-150.

Jurdi, R, Hage, H.S., \& Chow, H.P.H. (2012). What behaviours do students consider academically dishonest? Findings from a survey of Canadian undergraduate students. Social Psychology Education, 15, 1-23.

Kohlberg, L. (1984). Essays on moral development. Vol 2, The psychology of moral development: the nature and validity of moral. San Francisco: Harper \& Row.

Maeda, Y., Thoma, S.J., \& Bebeau, M.J. (2009). Understanding the relationship between moral judgment development and individual characteristics: The role of educational contexts. Journal of Educational Psychology, 101(1), 233-247.

Mavrinac, M., Brumini, G., Bilic-Zulle, L. \& Petrovecki, M. (2010). Construction and validation of attitudes toward plagiarism questionnaire. Basic Science, 195-201.

Milgram, S. (1974). Obedience to Authority: An Experimental View. New York: Harper \& Row.

Nisan, M. (1991). The moral balance model: theory and research extending our understanding of moral choice and deviation. In Handbook of Moral Behavior and Development, ed. W.M. Kurtines, J.L. Gewirtz, pp. 213-249. Hillsdale, NJ: Erlbaum.

Orlenius, K. (2008). Tolerance of intolerance: values and virtues at stake in education. Journal of Moral Education, 37(4), 467-484.

Rest, J.R. (1986). Moral Development: Advances in Research and Theory. New York: Praeger. 
Selwyn, N. (2008). 'Not necessarily a bad thing ...': a study of online plagiarism amongst undergraduate students. Assessment \& Evaluation in Higher Education. (5) 33, 465-479.

Sormunen, E. \& Lethiö, L. (2011). Authoring Wikipedia articles as an information literacy assignment - copy-pasting or expressing new understanding in one's own words? Information Research, 16 (4) paper 503. Available at http://InformationR.net/ir/16-4/paper503.html

Sutherland-Smith, W (2010). Retribution, deterrence and reform: the dilemmas of plagiarism management in universities. Journal of Higher Education Policy and Management, (1)32. 5-16.

Tangney, J.P., Stuewig, J., \& Mashek, D.J. (2007). Moral emotions and moral behavior. Annual Review of Psychology, 58, 345-372.

Voelker, T.A., Love, L.G., \& Pentina, I. (2012). Plagiarism: What don't they know? Journal of Education for Business, 87, 36-41.

\section{Appendix}

\section{Part one:}

\section{Is it okay?}

1. To copy a text and refer to it, but leave out quotation marks and thereby give the impression that the text is your own

2. To write in your own words information from written text, without stating the references

3. To refer to a book or article without having read the original text

4. To leave out results which are not in line with your main results

5. To use someone else's idea without referring to him/her as the sources of information

6. To cooperate with another student on an individual examination paper, that results in similaranswers

7. To re-use your text from previous papers, without referring to yourself

8. To help a friend by doing his/her homework

9.To use parts of a text written by a friend and add the same amount of text written by yourself, and hand it in with your own name on it

10.To summarize course literature for each other instead of reading it all by yourselves

\section{Alternatives at each item (a 5-point Likert scale)}

Yes, absolutely $\longmapsto+$

\section{Part two:}

11. Carl has copied four sentences from a text and referred to the source. However, he has omitted the quotes and it looks like he has produced the text by himself.

It could be two reasons for his action:

Carl has forgotten (failed) to mark by quotes

or that

Carl has deliberately omitted marking by quotes

- Do you find alternative (a) as a matter of cheating?

Yes, absolutely

- Do you find alternative (b) as a matter of cheating?

Yes, absolutely $\longmapsto+1,1+1$ No, absolutely not

Justification of the answer:

12. Carl has copied twenty sentences from a text and referred to the source. However he has omitted the quotes and that looks like he has produced the text by himself.
It could be two reasons for his action:

Carl has forgotten (failed)to mark by quotes

or that

Carl has deliberately omitted marking by quotes

- Do you find alternative (a) as a matter of cheating?

Yes, absolutely Justification of the answer:

- Do you find alternative (b) as a matter of cheating?

Yes, absolutely Justification of the answer:

13.Carin has right now finished the work with her degree project. All the theoretical framework (five pages) is picked up from her previous examination paper. However, she has not referred to her formerly produced text.

Do you consider this a form of cheating?

Yes, absolutely Justification of the answer:

14.A student writes the text below after have been reading about the history of pharmaceutical products in some various textbooks.

Man discovered early that contains in some plants could be healthy and be used as cure for illness. During our eldest culture these plants were widely known and used. For instance, it is known that some plants were used in China 7000 years ago. Herbs were also used as medicine in the Egypt and other old cultures.

Do you consider the student should refer to some source in this case?

Yes, absolutely $1+1+1$ No, absolutely not Justification of the answer:

15. [An excerpt from an original textbook is presented for the participants and text 2 is a paraphrase

of this one and without any reference from text no 1.]

Do you consider this a form of cheating?

Yes, absolutely Justification of the answer:

16. If yes: Do you think this a case like this should be reported to the local discipline board?

Yes, absolutely Justification of the answer:

17. Some students are discussing attitudes towards cheating and they argue as following:

Anna: - I don't care if somebody cheats. It's their business...

Bengt: - But it's unfair towards those who exert themselves

Cissi: - Well, but life is not fair, some people have less prerequisites than others so it could be

okay if it helps themselves.

David: - I think it's wrong to be dishonest

Erika: - So many other people are cheating in the society so it doesn't matter...

Whose statement do you agree with? Anna 


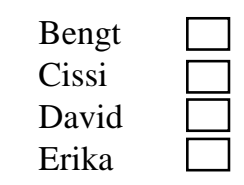

Comments:

\section{Part 3:}

\section{Is it okay?}

18. it Ok not to tell the cashier if you have paid 10 euro too little for a product in the shop?

19. it okay to share your private copied action films on Internet (eg. by file sharing)?

20. it okay to keep 100 euro from a founded wallet (without name)?

\section{Alternatives at each item (a 5-point Likert scale)}

Yes, absolutely

21. Carl has bought a new computer, borrow a cd with Office and thereby evade the copy protection. Do you find that okay?

Justification of the answer:

22. You enter the bank for picking up 500 euro. When you have returned to the car you turn out that you have received 600 euro, even if the receipt says 500 euro. Do you return and correct the fault?

Justification of the answer:

23. You go by train and have planned for buying ticket on the train. However, the ticket-collector passes by since he thought you had entered the train earlier. Next time he passes by, do you ask him for buying a ticket?

Justification of the answer:

\section{Notes on Contributors}

Anna-Carin Jonsson is a Docent/Assoc. Professor in Educational Work at University of Borås. Her research concerns metacognition, intelligence, learning, ethics in higher education, stereotypes, implicit theories, and examination.

Kennert Orlenius is a professor in Educational Work at University of Borås. His research interest regards values education, including norms and values in higher education as well as professional ethics. 